\title{
Short-term memory loss over time without retroactive stimulus interference
}

\author{
Nelson Cowan and Angela M. AuBuchon \\ University of Missouri, Columbia, Missouri
}

\begin{abstract}
A key question in cognitive psychology is whether information in short-term memory is lost as a function of time. Lewandowsky, Duncan, and Brown (2004) argued against that memory loss because forgetting in serial recall occurred to the same extent across serial positions regardless of the rate of recall. However, we believe Lewandowsky et al. (2004) only prevented one of two types of rehearsal; they did not prevent nonarticulatory rehearsal via attention. To prevent articulatory and nonarticulatory rehearsal without introducing interference, we presented unevenly timed stimuli for serial recall and, on some trials, required that the timing of stimuli be reproduced in the response. In those trials only, evidence of memory loss over time emerged. Further research is needed to identify whether this memory loss is decay or lost distinctiveness.
\end{abstract}

A basic enigma of cognition is whether information is lost as a function of time. A long research tradition suggests that information is lost because of interference, but not time per se (see, e.g., Bjork \& Whitten, 1974; Crowder, 1993; Lovatt, Avons, \& Masterson, 2002; McGeoch, 1932; Melton, 1963; Nairne, 2002; Neath \& Surprenant, 2003; Oberauer \& Kliegl, 2006; Service, 1998; Waugh \& Norman, 1965). Yet, various theorists have assumed that unrehearsed information is lost across several seconds (e.g., Baddeley, 1986; Broadbent, 1958; Cowan, 1988; Page \& Norris, 1998; Towse, Hitch, \& Hutton, 2000), as some evidence suggests (e.g., Baddeley \& Scott, 1971; Cowan, Nugent, Elliott, \& Geer, 2000; Cowan, Saults, \& Nugent, 1997; Darwin, Turvey, \& Crowder, 1972; Mueller, Seymour, Kieras, \& Meyer, 2003; Reitman, 1974; Watkins, Watkins, Craik, \& Mazuryk, 1973). The issue remains unresolved.

It is unlikely that one study can resolve the issue, but the present work assesses memory loss over short time periods, despite a recent study strongly arguing against it (Lewandowsky, Duncan, \& Brown, 2004). Lewandowsky et al. (2004) presented six letters from the same fixed set in a different random order on each trial and required fast, medium, or slow serial recall. This was achieved in one experiment by training the speed of keyboard-based recall to be $0.4,0.8$, or $1.6 \mathrm{sec}$ per item, with or without repetition of the word super during recall as articulatory suppression to prevent covert verbal rehearsal. It was achieved in a second experiment by requiring that the word super be repeated once, twice, or thrice between successive items as the list was verbally recalled. No significant difference between recall rates was observed. It was concluded that temporal delays cannot influence serial recall.

Our concern is that articulatory suppression may not prevent all types of rehearsal. If not, the possibility re- mains that another type of rehearsal counteracted memory loss. Cowan (1992) proposed that a non-articulation-based type of rehearsal results from a mental search through short-term memory to determine which item to recall next; that may reactivate items in short-term memory. The nonarticulatory nature of this process is supported by evidence that pauses in recall, during which this search and reactivation presumably occurs, lengthen as a function of list length, but not as a function of word length (Cowan et al., 1994). There appears to be some sort of list-wide search of lexical nodes, independent of word length, during pauses. It may have prevented memory loss over time in Lewandowsky et al. (2004).

Barrouillet, Bernardin, and Camos (2004) and Barrouillet, Bernardin, Portrat, Vergauwe, and Camos (2007) proposed decay, along with the assumption that verbal distraction can prevent all rehearsal. Verbal distraction could serve as articulatory suppression and also prevent non-articulation-based rehearsal, such as the memory search process of Cowan (1992). In contrast, repetition of a single word is much less distracting and should not prevent nonarticulatory rehearsal. Barrouillet et al. (2004) presented consonants to be recalled and, in some experiments, random series of numbers to be read aloud between consonants in the presentation. They found that the faster the rate of number reading between items, the poorer the recall of consonants. In fact, span was a linear function of the rate of number reading. The theoretical account stated that the consonants were vulnerable to decay except during the portions of the presentation when the participant was not distracted by the number-reading task. The faster number-reading occurred, the higher the proportion of time during which decay, rather than reactivation, presumably occurred, and, therefore, the poorer performance

N. Cowan, cowann@missouri.edu 
was. Articulatory suppression between item presentations in place of number reading produced less memory loss, presumably because it failed to suppress a nonarticulatory type of rehearsal as did number reading.

One could test the assumptions of Barrouillet and colleagues in the context of Lewandowsky et al. (2004) by requiring that random numbers be read between recalled items. However, if memory loss over time were observed in that circumstance, an additional objection could be raised. The numbers being read may serve as interference (despite the dissimilarity between numbers and the letters to be retained). What is needed is a way to introduce distraction without interference. Sufficient distraction might prevent both types of rehearsal and allow memory loss over time to emerge.

In the present serial recall experiment, the stimuli were lists of seven printed digits to be recalled aloud. Two manipulations were used to elicit memory loss over time. (1) We manipulated the lengths of the first and second halves of the list independently (the lengths of Interitem Intervals $1-3$ versus $4-6$ out of six intervals). The blank interitem intervals in each half-list could be $0.5 \mathrm{sec}$ or $2.0 \mathrm{sec}$. Filler trials with random intervals between items also were included, to help camouflage the pattern of item timing. (2) We also manipulated the recall instructions presented after each list. In the paced-timing condition, the participant was to recall the items in the same timing pattern in which they were presented, whereas in the freetiming condition, the participant could recall the items at whatever rate seemed optimal, still in the presented order.

With uneven timing on most trials, having to repeat the exact timing of items in a list in the paced condition was expected to impede mechanisms subserving covert verbal rehearsal. Prior research shows that tapping in an uneven rhythm (but not steady tapping) has an effect on short-term verbal recall similar to the effect of articulatory suppression (Larsen \& Baddeley, 2003; Saito, 1994); we supposed that remembering list timing would function similarly. We further anticipated that remembering the timing would impose an additional memory load that would be sufficiently distracting to prevent the nonarticulatory type of rehearsal in the paced-timing condition.

If no loss of memory were observed as a function of silent time during recall in the paced-timing condition, we would not know whether it was because there is no loss or because our assumptions about paced recall are unrealistic. However, if such time-dependent loss is observed despite the absence of interfering stimuli during recall, this novel finding would suggest that Lewandowsky et al. (2004) did not suppress all kinds of rehearsal.

Of primary interest are effects of long time intervals not only for items adjacent to those intervals, but also for items recalled later in the list. The literature leads to different expectations for length effects in the paced- and free-timing conditions. In the paced-timing condition, presumably participants cannot rehearse during recall. Then it should be detrimental to recall if the interitem intervals are long, allowing more time for decay. A long first half-list should be more detrimental than a long second half-list because each interitem interval in the response delays recall of only subsequent items. Similar logic was described for studies in which word length was manipulated within the first and second halves of lists (Cowan et al., 1992, 2000).

These predictions based on recall timing are, however, discrepant from predictions based on effects of the intervals on processes taking place during the presentation of the list. For printed lists such as these, past research indicates that longer intervals between items improve recall (e.g., Penney, 1975). If this occurs because longer intervals allow more time for rehearsal (Barrouillet et al., 2004), then there should be the greatest benefit from longer intervals at the end of the list, when there is the most information to be rehearsed. Note that these expectations are the opposite of what would be expected if participants could not rehearse during the intervals, as is the case when the intervals are filled with a distracting task (Towse et al., 2000).

In the paced-timing condition, the two effects that we have described might counteract one another. However, in the free-timing condition, recall can be at any pace, so the finding clearly should favor long intervals, and especially a long second half, facilitating rehearsal during presentation. The key prediction is an interaction of recall instructions and first half-list length, in which paced timing produces poorer recall than free timing if the first half-list is long because a pacing requirement then delays the recall of most list items.

\section{METHOD}

\section{Participants}

Twenty-five college students ( 14 female, 11 male) participated for course credit. We omitted another participant, who failed to follow instructions.

\section{Apparatus, Stimuli, and Procedure}

In a quiet room, stimuli appeared on the computer screen in the ordinary 12-point font in white lettering on a black background. The stimuli came from the set of digits 1-9. Each trial began with the printed message "Get Ready" for $1 \mathrm{sec}$, followed immediately by the first digit. Each digit lasted $0.5 \mathrm{sec}$ and was followed immediately by "xxx" as a mask, for $0.2 \mathrm{sec}$. A variable blank interitem interval followed each mask.

The last item's mask was followed by a 0.5 -sec blank interval and then by the word FREE or PACE. Upon FREE, the participant was to recall orally the digits in the presented order, at any pace that was comfortable. However, upon PACE, they were to recall orally the digits in the presented order using a timing matching that in which the list was presented. These responses were recorded for later analysis. After each trial's recall, a keypress yielded feedback in which the digits were now presented concurrently on a single line, spaced apart in a way approximately proportional to the timing pattern that had been presented. The participant could examine the feedback as long as he or she desired before initiating the next trial. The spoken responses were recorded digitally and later scored by serial position.

The timing of trials differed in the duration of the first three and the last three of the six interitem blank intervals, which were most often short $(0.5 \mathrm{sec})$ or long $(2.0 \mathrm{sec})$. The four critical trial types thus were short-short, short-long, long-short, and long-long. For example, the long-short trial type consisted of (digit, mask, blank $2.0 \mathrm{sec}$ ) for the first three digits, (digit, mask, blank $0.5 \mathrm{sec}$ ) for the next three digits, and then the final digit. There also were filler trials in which each of the six blank intervals was of a duration randomly selected from any point in the range of 0 to $2.5 \mathrm{sec}$. Each block of 12 trials included 6 free-timing trials ( 1 of each critical trial types and 2 filler trials) and 6 paced-timing trials of the same types. These 12 trials occurred 
in a new random order in each trial block. The first block served as practice, followed by 6 test blocks of 12 trials, totaling 72 test trials.

\section{RESULTS AND DISCUSSION}

\section{Timing-of-Recall Manipulation Check}

The timing of recall for correctly recalled lists was measured manually, one trial at a time, on computer with a waveform editor, by listening while setting markers on the response waveform. This method has produced highly reliable timing measurements (e.g., Cowan et al., 2006). Table 1 shows the timing results for correctly recalled lists of each trial type averaged across all available participants. Most participants had no correct trial to be timed in at least one trial type, and thus different subsets of participants contributed to the means for each trial type.

To assess the effectiveness of the recall timing manipulation, we examined the timing of the first and second halves of the lists separately, in participants with timed trials at all four length combination conditions, for the paced and then the free timing condition. The paced trials yielded the anticipated differences in response timing. In the measurements of the first half of the list, recall was faster for trials with a short first half $(M=2.59 \mathrm{sec}, S E M=0.31)$ than for trials with a long first half $(M=3.66 \mathrm{sec}, S E M=0.35)$ $\left[F(1,15)=12.90, p<.01, \eta_{\mathrm{p}}^{2}=.46\right]$. In that analysis, no other effect was obtained. In the measurements of the second half of the list, recall was faster for trials with a short second half $(M=2.88 \mathrm{sec}, S E M=0.29)$ than with a long second half $(M=3.98 \mathrm{sec}, S E M=0.31)[F(1,15)=16.10$, $\left.p<.01, \eta_{\mathrm{p}}^{2}=.52\right]$. There was also an interaction between the lengths of the first and second half-lists in the presentation $\left[F(1,15)=12.53, p<.01, \eta_{\mathrm{p}}^{2}=.46\right]$. The effect of the second half-list length was more pronounced when the first half-list was short (second half short, $2.54 \mathrm{sec}$; long, $4.29 \mathrm{sec}$ ) than when the first half-list was long (second half short, $3.22 \mathrm{sec}$; long, $3.66 \mathrm{sec}$ ). Paced recall of a long first half-list may have precipitated forgetting of the timing of the second half-list.

Table 1

Timing of First and Second Halves Within Correctly Recalled Lists

\begin{tabular}{|c|c|c|c|c|c|}
\hline \multirow[b]{2}{*}{ List Timing } & \multicolumn{2}{|c|}{$\begin{array}{c}\text { First } \\
\text { Half-List }^{\mathrm{a}}\end{array}$} & \multicolumn{2}{|c|}{$\begin{array}{c}\text { Second } \\
\text { Half-List }^{\mathrm{b}}\end{array}$} & \multirow[b]{2}{*}{$n$} \\
\hline & $M$ & $S D$ & $M$ & $S D$ & \\
\hline \multicolumn{6}{|c|}{ Free Timing of Recall } \\
\hline Short-short & 1.34 & 0.52 & 1.36 & 0.47 & 22 \\
\hline Short-long & 1.36 & 0.48 & 1.57 & 0.72 & 24 \\
\hline Long-short & 1.48 & 1.03 & 1.33 & 0.59 & 23 \\
\hline Long-long & 1.41 & 0.51 & 1.22 & 0.29 & 25 \\
\hline \multicolumn{6}{|c|}{ Paced Timing of Recall } \\
\hline Short-short & 2.62 & 1.12 & 2.75 & 1.41 & 18 \\
\hline Short-long & 2.65 & 1.30 & 4.50 & 1.64 & 23 \\
\hline Long-short & 3.45 & 1.42 & 3.02 & 1.31 & 19 \\
\hline Long-long & 4.05 & 1.66 & 3.88 & 1.39 & 24 \\
\hline
\end{tabular}

Note-List timing refers to the duration of pauses within the first and second halves of the list. Short and long pauses were 0.5 and $2.0 \mathrm{sec}$ long, respectively. a Measured from the beginning of the first word to the beginning of the fourth word. bMeasured from the beginning of the fourth word to the beginning of the seventh word.
Importantly, the timing measurements for the freetiming-of-recall condition did not yield comparable effects. For the measurement of the first half-list, there were no effects of the timing of presentation. For the measurement of the second half-list, a short first half resulted in a longer second-half response $(M=1.42 \mathrm{sec}, S E M=$ $0.09)$ than did a long first half $(M=1.20, S E M=0.07)$ $\left[F(1,18)=12.47, p<.01, \eta_{\mathrm{p}}^{2}=.41\right]$. The reason is uncertain but could have to do with a greater need to engage in retrieval processes during recall (Cowan et al., 2003) when the first half-list allowed little time for encoding. Any such effect presumably was obscured when there was a pacing requirement.

Finally, as is clear from Table 1, both the first- and second-half-list response times were much shorter under a free timing of recall $(M=1.29 \mathrm{sec}, S E M=0.11)$ than under paced timing $(M=3.10, S E M=0.28)[F(1,13)=$ $\left.70.19, p<.001, \eta_{\mathrm{p}}^{2}=.84\right]$. This was true even for the lists with both halves short (free $M=1.38, S E M=0.11$; paced $M=2.57, S E M=0.28)\left[F(1,16)=24.14, p<.001, \eta_{\mathrm{p}}^{2}=\right.$ .60]. Participants' preferred response speeds, which were considerably faster than the critical trials' fastest onset-toonset presentation rate of $1.2 \mathrm{sec}$, make sense if participants are trying to avoid forgetting over time.

\section{Accuracy of Recall}

The proportion correct was entered into a $2 \times 2 \times 2 \times 7$ ANOVA with free versus paced recall instructions, a short versus long first half-list, a short versus long second halflist, and serial position as within-subjects factors. The key findings were that performance with free timing of recall $(M=.73, S E M=.19)$ was better than performance with paced timing $(M=.68, S E M=.02)[F(1,24)=$ $\left.13.23, p<.01, \eta_{\mathrm{p}}^{2}=.36\right]$, and that the free versus paced recall instruction interacted with the first half-list length $\left[F(1,24)=4.35, p<.05, \eta_{\mathrm{p}}^{2}=.15\right]$ as shown in Figure 1, in conformity with the logic we have articulated if one assumes memory loss over time during recall only in the paced-timing condition.

In Figure 2, the nature of the recall timing instruction effects can be observed in more detail, across serial positions. The instructions interacted with serial position $\left[F(6,144)=5.31, p<.001, \eta_{\mathrm{p}}^{2}=.18\right]$. It is clear from the figure that performance dropped more quickly across serial positions when the recall timing was paced than when it was free. That could occur either because paced recall was slower or because paced recall prevented rehearsal during recall. One can see also that the discrepancy between recall-timing conditions was accentuated when the first half-list was long, especially in the condition in which the entire list was long. In that condition, there is the largest passage of time before recall is completed. There were no other interactions with recall instructions.

Another noteworthy effect is that a short second halflist was detrimental to recall regardless of timing instructions $\left[F(1,24)=13.36, p<.01, \eta_{\mathrm{p}}^{2}=.36\right]$, and that this difference increased across serial positions $[F(6,144)=$ $\left.8.16, p<.001, \eta_{\mathrm{p}}^{2}=.25\right]$, as shown in Figure 2. (Proportions in the first and third panels are less than those in the second and fourth.) A short second half-list may be espe- 


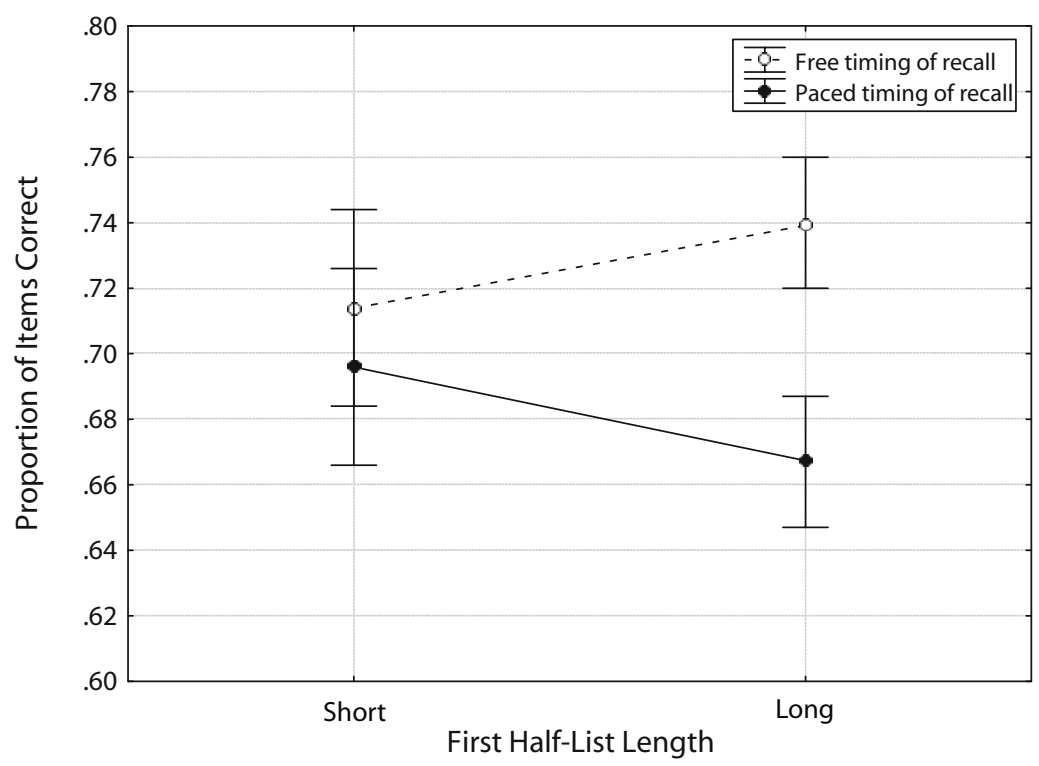

Figure 1. Proportion of items correct for each recall-timing condition (graph parameter) for trials with short versus long interitem intervals in the first half-list. Item onset-to-onset times were 1.2 sec for short intervals and 2.7 sec for long intervals. Error bars are standard errors.
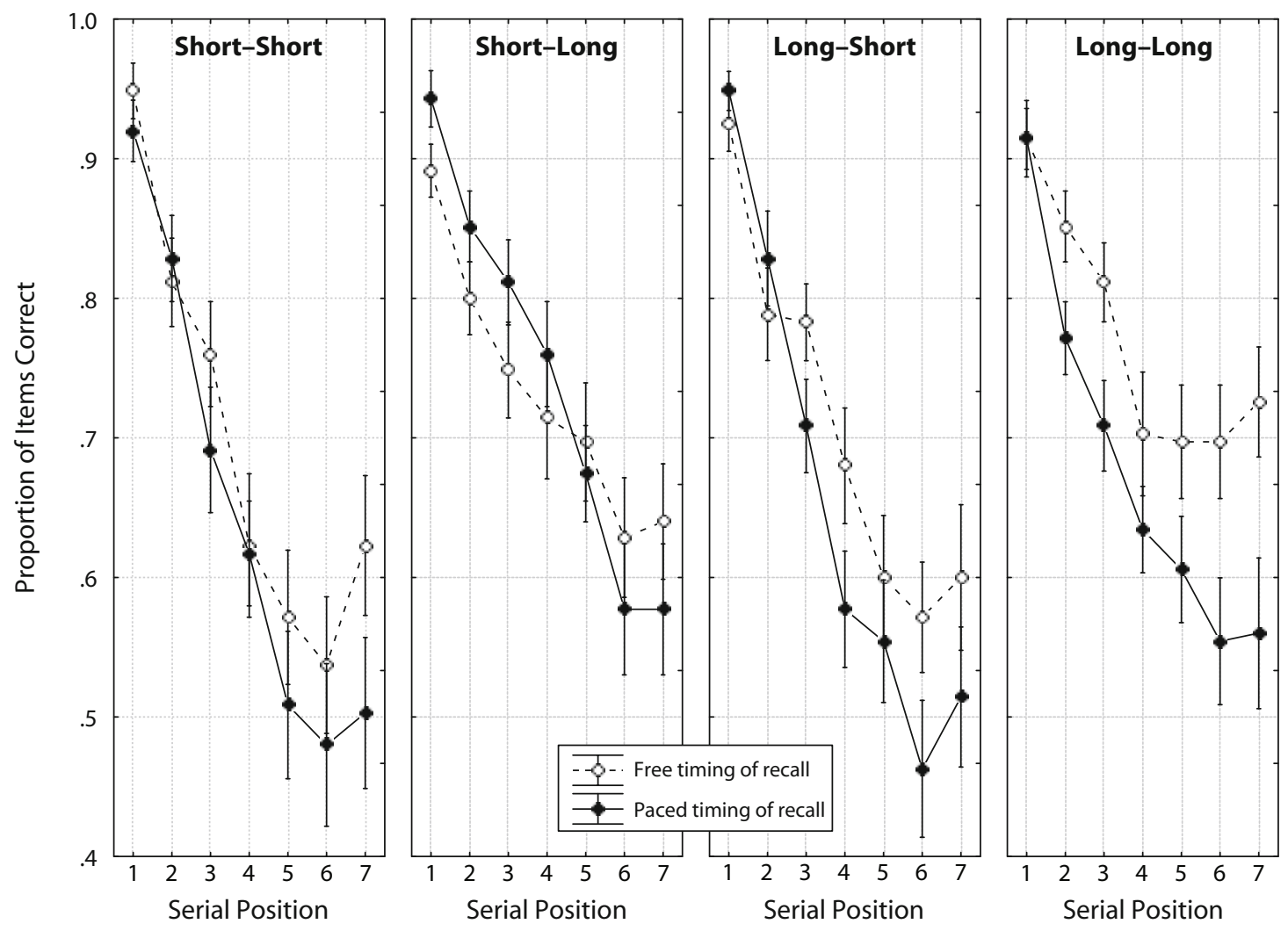

Figure 2. Proportion of items correct at each serial position in each recall-timing condition (graph parameter) for each combination of first and second half-list interitem interval lengths. For example, the panel marked "short-long" includes trials with three short intervals followed by three long ones. Item onset-to-onset times were 1.2 sec for short intervals and $2.7 \mathrm{sec}$ for long intervals. Error bars are standard errors. 
cially detrimental to encoding and rehearsal during the list presentation, or it may reduce the temporal distinctiveness of items (e.g., Bjork \& Whitten, 1974).

In the critical, paced condition, the effect of first-half-list length was significant according to post hoc Newman-Keuls pairwise comparisons only when the second half was long (in which case short first half $M=.74$; long first half $M=$ .68). In that situation, examined for each serial position separately, the advantage of a short over a long first half was $.03, .08, .10, .13, .07, .02$, and .02 .

We asked whether the performance functions shown in Figure 2 could result simply from decay across the time periods specified in Table 1. We believe that they cannot; something must affect performance other than decay over time. To investigate this, we based group predictions on list timing conforming to Table 1, and with a pace of recall even across the three words within each list half. We entered these times into the decay formula of W. Wickelgren described by Wixted and Carpenter (2007). With variations of the three parameter values in the formula, it could not approximate the data shown in Figure 2. Depending on the value of the parameters, the curve could drop off too suddenly or too gradually, but it could not resemble the obtained functions in which performance dropped steeply for four to six serial positions and then leveled off or reversed for the remaining few serial positions. It also could not produce functions like those shown for trials with a short first half, which display a marked emergence of a free-timing advantage only for the last three serial positions.

Instead of pure decay, a theoretical model that could work is one in which, in the free-timing condition, the later serial positions can be maintained in short-term memory while earlier list items are recalled. In the pacedtiming condition, the added response delay during which rehearsal is prevented can cause items that were just moderately well-encoded (especially Serial Positions 2-5 when the second half-list was long) to be lost as a function of the time elapsed.

According to the SIMPLE model of memory (Brown, Neath, \& Chater, 2007; Lewandowsky, Nimmo, \& Brown, in press), the temporal isolation of items in a list is beneficial to recall when the importance of timing is stressed at recall. This runs counter to the present findings regarding the length of the first half-list in the paced condition. However, these results might still be explained by SIMPLE if it is assumed that the benefit of temporal isolation during presentation is more than counteracted by the loss of temporal distinctiveness during long delays in responding.

\section{CONCLUSION}

This study challenges the conclusion of Lewandowsky et al. (2004) that there is no detriment of the passage of time during recall of items in immediate serial recall. Lewandowsky et al. (2004) prevented articulation-based covert rehearsal but may not have prevented other types of rehearsal. We were apparently able to do that without introducing stimulus interference, for variably timed lists, by requiring that the timing of the presentation be reproduced in recall on some trials. Those trials showed a detrimental effect of a lengthy first half-list on recall. We cannot rule out a role of interference from internal processing during the interitem delays in recall. It is also not clear whether the effect of time results from memory decay or loss of distinctiveness during recall (e.g., Bjork \& Whitten, 1974; Brown et al., 2007). The findings call for further behavioral and neurological research on the role of time in memory.

\section{AUTHOR NOTE}

We acknowledge NIH Grant R01 HD-21338. We thank Andrea Kanevsky, Lara Nugent, Emily Elliott, and Anna Hismjatullina for pilot work. Correspondence concerning this article should be addressed to N. Cowan, Department of Psychological Sciences, University of Missouri, $18 \mathrm{Mc}-$ Alester Hall, Columbia, MO 65211 (e-mail: cowann@missouri.edu).

\section{REFERENCES}

Baddeley, A. D. (1986). Working memory. Oxford: Oxford University Press, Clarendon Press.

Baddeley, A. D., \& ScotT, D. (1971). Short-term forgetting in the absence of proactive inhibition. Quarterly Journal of Experimental Psychology, 23, 275-283.

Barrouillet, P., Bernardin, S., \& Camos, V. (2004). Time constraints and resource sharing in adults' working memory spans. Journal of Experimental Psychology: General, 133, 83-100.

Barrouillet, P., Bernardin, S., Portrat, S., Vergaume, E., \& Camos, V. (2007). Time and cognitive load in working memory. Journal of Experimental Psychology: Learning, Memory, \& Cognition, 33, 570-585.

BJork, R. A., \& Whitten, W. B. (1974). Recency-sensitive retrieval processes in long-term free recall. Cognitive Psychology, 6, 173-189.

Broadbent, D. E. (1958). Perception and communication. New York: Pergamon.

Brown, G. D. A., Neath, I., \& Chater, N. (2007). A temporal ratio model of memory. Psychological Review, 114, 539-576.

CowAN, N. (1988). Evolving conceptions of memory storage, selective attention, and their mutual constraints within the human information processing system. Psychological Bulletin, 104, 163-191.

Cowan, N. (1992). Verbal memory span and the timing of spoken recall. Journal of Memory \& Language, 31, 668-684.

Cowan, N., Day, L., Saults, J. S., Keller, T. A., Johnson, T., \& FlorES, L. (1992). The role of verbal output time in the effects of word length on immediate memory. Journal of Memory \& Language, 31, 1-17.

Cowan, N., Elliott, E. M., Saults, J. S., Nugent, L. D., Bomb, P., \& Hismuatullina, A. (2006). Rethinking speed theories of cognitive development: Increasing the rate of recall without affecting accuracy. Psychological Science, 17, 67-73.

Cowan, N., Keller, T., Hulme, C., Roodenrys, S., McDougall, S., \& RACK, J. (1994). Verbal memory span in children: Speech timing clues to the mechanisms underlying age and word length effects. Journal of Memory \& Language, 33, 234-250.

Cowan, N., Nugent, L. D., Elliott, E. M., \& Geer, T. (2000). Is there a temporal basis of the word length effect? A response to Service (1998). Quarterly Journal of Experimental Psychology, 53A, 647-660.

Cowan, N., Saults, J. S., \& Nugent, L. D. (1997). The role of absolute and relative amounts of time in forgetting within immediate memory: The case of tone pitch comparisons. Psychonomic Bulletin \& Review, 4, 393-397.

Cowan, N., Towse, J. N., Hamilton, Z., Saults, J. S., Elliott, E. M., LACEY, J. F., ET AL. (2003). Children's working-memory processes: A response-timing analysis. Journal of Experimental Psychology: General, 132, 113-132.

Crowder, R. G. (1993). Short-term memory: Where do we stand? Memory \& Cognition, 21, 142-145.

Darwin, C. J., Turvey, M. T., \& Crowder, R. G. (1972). An auditory analogue of the Sperling partial report procedure: Evidence for brief auditory storage. Cognitive Psychology, 3, 255-267.

Larsen, J. D., \& Baddeley, A. D. (2003). Disruption of verbal STM 
by irrelevant speech, articulatory suppression, and manual tapping: Do they have a common source? Quarterly Journal of Experimental Psychology, 56A, 1249-1268.

Lewandowsky, S., Duncan, M., \& Brown, G. D. A. (2004). Time does not cause forgetting in short-term serial recall. Psychonomic Bulletin \& Review, 11, 771-790.

Lewandowsky, S., Nimmo, L. M., \& Brown, G. D. A. (in press). When temporal isolation benefits memory for serial order. Journal of Memory \& Language.

Lovatt, P., Avons, S. E., \& Masterson, J. (2002). Output decay in immediate serial recall: Speech time revisited. Journal of Memory \& Language, 46, 227-243.

McGeoch, J. A. (1932). Forgetting and the law of disuse. Psychological Review, 39, 352-370.

Melton, A. W. (1963). Implications of short-term memory for a general theory of memory. Journal of Verbal Learning \& Verbal Behavior, 2 , $1-21$.

Mueller, S. T., Seymour, T. L., Kieras, D. E., \& Meyer, D. E. (2003). Theoretical implications of articulatory duration, phonological similarity, and phonological complexity in verbal working memory. Journal of Experimental Psychology: Learning, Memory, \& Cognition, 6, 1353-1380.

NAIRNE, J. S. (2002). Remembering over the short-term: The case against the standard model. Annual Review of Psychology, 53, 53-81.

Neath, I., \& Surprenant, A. (2003). Human memory (2nd ed.). Belmont, CA: Wadsworth.

Oberauer, K., \& Kliegl, R. (2006). A formal model of capacity limits in working memory. Journal of Memory \& Language, 55, 601-626.
Page, M. P. A., \& Norris, D. G. (1998). The primacy model: A new model of immediate serial recall. Psychological Review, 105, 761-781.

Penney, C. G. (1975). Modality effects in short-term verbal memory. Psychological Bulletin, 82, 68-84.

Reitman, J. S. (1974). Without surreptitious rehearsal, information in short-term memory decays. Journal of Verbal Learning \& Verbal Behavior, 13, 365-377.

SAITO, S. (1994). What effect can rhythmic finger tapping have on the phonological similarity effect? Memory \& Cognition, 22, 181-187.

SERVICE, E. (1998). The effect of word length on immediate serial recall depends on phonological complexity, not articulatory duration. Quarterly Journal of Experimental Psychology, 51A, 283-304.

Towse, J. N., Hitch, G. J., \& HutTon, U. (2000). On the interpretation of working memory span in adults. Memory \& Cognition, 28, 341-348.

Watkins, M. J., Watkins, O. C., Craik, F. I. M., \& Mazuryk, G. (1973). Effect of nonverbal distraction of short-term storage. Journal of Experimental Psychology, 101, 296-300.

Waugh, N. C., \& Norman, D. A. (1965). Primary memory. Psychological Review, 72, 89-104.

Wixted, J. T., \& CARPEnter, S. K. (2007). The Wickelgren Power Law and the Ebbinghaus Savings Function. Psychological Science, 18, 133-134.

(Manuscript received May 12, 2007; revision accepted for publication June 23, 2007.)

\section{Notices AND ANNOUNCEMENTS}

\section{Nominations for Editorship of \\ Behavior Research Methods}

The Publications Committee of the Psychonomic Society solicits nominations for the editorship of Behavior Research Methods. The present editor, John H. Krantz, will stop receiving manuscripts on December 31, 2008; his official term expires at the end of 2009. The Publications Committee of the Psychonomic Society expects to appoint the new editor by June 2008. The new editor will begin to receive manuscripts January 1, 2009; his or her official 5-year term will begin January 1, 2010.

Nominations, including self-nominations, and queries should be sent via e-mail no later than February 28, 2008, to Jonathan Vaughan, the chair of the Behavior Research Methods search committee: jvaughan@hamilton.edu.

\section{Nominations for Editorship of Memory \& Cognition}

The Publications Committee of the Psychonomic Society solicits nominations for the editorship of Memory \& Cognition. The present editor, Brian H. Ross, will stop receiving manuscripts on December 31, 2008; his official term expires at the end of 2009. The Publications Committee of the Psychonomic Society expects to appoint the new editor by June 2008. The new editor will begin to receive manuscripts January 1, 2009; his or her official 5-year term will begin January 1, 2010.

Nominations, including self-nominations, and queries should be sent via e-mail no later than February 28, 2008, to Nelson Cowan, the chair of the Memory \& Cognition search committee: cowann@missouri.edu. 